\title{
COMPARATIVE ASSESSMENT OF ROAD RATING SYSTEMS
}

\author{
OLUFIKAYO ADERINLEWO*1 \\ ${ }^{I}$ Department of Civil and Environmental Engineering, Federal University of Technology, \\ P.M.B. 704, Akure, Nigeria
}

\begin{abstract}
In this study, three road rating systems were assessed and compared after carefully applying them to five major road case studies. The essence of these rating systems is to provide a consistent, reasonably objective and systematic approach for establishing priorities and scheduling and budgeting roadway rehabilitation requirements. The effectiveness of these systems was measured during the road condition survey and compared with one another. The most effective system out of the three was determined based on the different types and severity levels of pavement distresses identified for the five different routes.
\end{abstract}

Keywords: rating systems, roadway rehabilitation, road condition, pavement distresses.

\section{INTRODUCTION}

A road is an identifiable route, way or path between two or more locations. Roads are typically paved or otherwise prepared to allow for easy travel. Historically many roads were simply recognizable routes without any formal construction or maintenance. The primary function of any road is to safely and smoothly carry vehicular traffic from one point to another [1].

Basically, pavements have been divided into two broad categories namely flexible and rigid pavements. A flexible pavement consists of a relatively thin wearing surface built over a base course which rests upon a compacted subgrade. In contrast, rigid pavements are made up of Portland cement concrete and may or may not have a base course between the wearing surface and the subgrade. The essential difference between the two types of pavements, flexible and rigid, is the manner in which they distribute load over the subgrade. A rigid pavement tends to distribute the load over a relatively wide area of soil because of its rigidity and high modulus of elasticity and hence, a major portion of the structural capacity is supplied by the slab itself unlike in a flexible pavement [2].

The main functions of a road pavement are to provide a smooth and good rolling surface, provide high resistance to surface wear and deformation, provide skid resistant surface, protect the underlying subgrade layer from detrimental actions of water and other natural agencies and distribute the wheel loads such that the layers underneath are not overstressed.

Roads are exposed to varying loading and environmental conditions. Hence, they experience distresses to different extents which may lead to failure and reduction in serviceability. Therefore, road maintenance and rehabilitation efforts are intended to restore ride quality, eliminate slipperiness of the surface and prevent structural deterioration as well as other surface defects. There are four factors which cause pavement defects namely increase in traffic, environmental changes, maintenance deficiencies and design/construction deficiencies [3].

\footnotetext{
* Corresponding author, email: oluade2010@ gmail.com

(C) 2016 Alma Mater Publishing House
} 
Five major routes/roads were identified and used as case studies in this research work and all five were flexible pavements. In flexible pavements, distress is defined by the presence of localized depressions or settlements. The depressions are normally followed by heaving which results in pavement failure [3].

Distress in the subgrade is usually due to two main reasons namely excessive stress application and inadequate stability, distress in the subbase or base course is usually due to inadequate strength, inadequate wearing course, lack of lateral confinement, loss of binding action, loss of materials and use of inferior materials while distress in the wearing course is usually due to lack of proper mix design, lack of good quality control and oxidation of the binder [4].

Based on the rating system used and the measurement of these distresses, the roads are assigned a rating that represents their overall condition. This score is termed the road condition rating which measures the route's overall performance [5]. Three types of road rating systems are considered in this study namely Present Serviceability Rating (PSR), Present Serviceability Index (PSI) and Pavement Condition Index (PCI).

This study therefore assesses the three road rating systems aforementioned with respect to five different travel routes and determines the most effective. The underlying objectives of this study are to determine the road performance of the five routes identified as case study, determine what parameters should be used to predict the performance of the roads under study and identify the most effective rating system.

\section{BACKGROUND LITERATURE}

Pavement performance is a function of its relative ability to serve traffic over a period of time [6]. Originally, this was determined subjectively by visual inspection and experience. However, such experience is difficult to transfer from one person to another and decisions made based on such data have been shown to be often inconsistent. In the late 1950's, systems of objective measurement were developed which could measure a pavement's condition and performance fairly accurately. Over the years, they have been refined and upgraded to provide more rapid and objective measurements which are used in making maintenance and rehabilitation decisions [7].

These systems assign a score or rating to the pavement based on a rating scale. Such pavement condition scores can be used to trigger treatment or determine when the pavement should be scheduled for maintenance and rehabilitation, determine the extent and cost of repair required, determine a network condition index and enable equal comparison of different pavements [8].

Furthermore, road rating systems help to establish maintenance priorities determine maintenance and rehabilitation strategies and predict pavement performance. Pavement performance is largely defined by evaluation of a number of characteristics namely roughness, surface distress, skid resistance and deflection [9].

\subsection{Present Serviceability Rating (PSR)}

Present serviceability rating is a number grade given to a pavement section based on the ability of that pavement to serve its intended traffic. It is based on the concept of serviceability to which the smoothness and rideability of the various pavement sections are related. Initially, serviceability ratings were obtained by a selected panel of highway users who individually rated each pavement route on an arbitrary scale ranging from 0 to 5 . A zero rating indicated that the pavement was impassable while a rating of 5 denoted an excellent pavement. The PSR scale is as shown in Figure 1. This measure of serviceability using ratings was termed the PSR. The average or mean rating by a panel is used for correlation purposes.

Basically, the PSR is a ride quality rating requiring panel of observers to actually ride in an automobile over the routes in question. It gives the condition of the pavement at an instant of time. It has the following characteristics: it is highly subjective, prone to error, possesses high possibility for central tendering and the raters have to be either trained or be experienced enough to make accurate judgement. Some applications of the PSR are that it can be used to estimate the remaining service life of a pavement and it allows prediction of the life of the pavement within reasonable limits. The factors considered in determining the PSR of a given section of road way are the ride quality, average rut depth and the age of the surface course. 


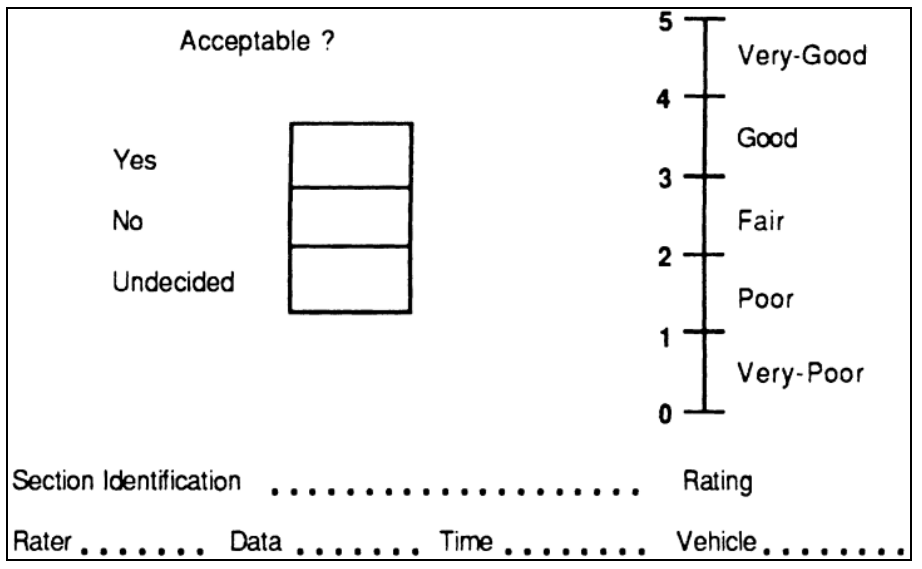

Fig. 1. Present Serviceability Rating Scale [10].

\subsection{Present Serviceability Index (PSI)}

The Present serviceability index is based upon the concept of correlating user opinions with measurements of road roughness, cracking, patching and rutting. The PSI was developed because of the lapses evident in the PSR due to its subjective nature.

Hence, an equation was developed for the PSI which relates the pavement ratings with the objective distress measurements. The equation is given as:

$$
\text { PSI }=5.02-1.9 \log \left(1+S_{v}\right)-1.38\left(R_{d}\right)^{2}-0.01(P+C)^{1 / 2}
$$

where: $S_{v}$ is the slope variance and a measure of the longitudinal pavement roughness; $R_{d}$ is the rut depth or average depth of the wheel path rut; $\mathrm{P}$ is the patching area; $\mathrm{C}$ is the cracking area.

The PSI has several uses namely that it permits the rating of pavements on a common basis, it permits the formulation of priority and maintenance programs in a logical manner, it establishes relationships between objective pavement measurements, it allows measurements to be obtained at various times based on the subjective ratings of the road users in the form of an equation.

\subsection{Pavement Condition Index (PCI)}

Pavement condition index is defined as an index that reflects the composite effects of varying distress types as well as the effect of different severity levels and their extent upon the overall condition of a road. PCI values range from 0 to 100 where 0 denotes a failed or very poor pavement while 100 denotes a very good pavement completely free of distress. Figure 2 shows the PCI scale. The PCI value is moderated by a cumulative deduct value score based upon the type, quantity, security level of distress and type of pavement.

The model for computing the PCI is based upon the summation of deduct points for each type of observable distress. Deduction for each distress type is calculated by multiplying distress weight by the weights of severity and extent of distress. Distress weight is the maximum number of deductible points for the different distress types. The mathematical expression for PCI is given as:

$$
\mathrm{PCI}=100-\sum_{\mathrm{i}=1}^{\mathrm{n}} \text { Deduct }
$$

where $\mathrm{n}$ is the number of observable distresses.

$$
\text { Deduct }=(\text { weight for distress }) \mathrm{x} \text { (weight of severity) } \mathrm{x} \text { (weight for extent). }
$$

Three levels of severity namely low, medium and high and three levels of extent (occasional, frequent and extensive) are considered. The deduct weights for each pavement type have been developed on the basis of the review of the rating methods developed in the United States, Europe and Canada and the experience gained from the rating methods developed by the resource staff as a result of studies conducted in this connection. Two premises were considered when assigning the weights namely overlay (and/or rehabilitation of high type multi- 
lane roadways should be considered when the rating drops within the range of 65 to 55) and deteriorated pavement (which normally exhibits several different types of distresses).

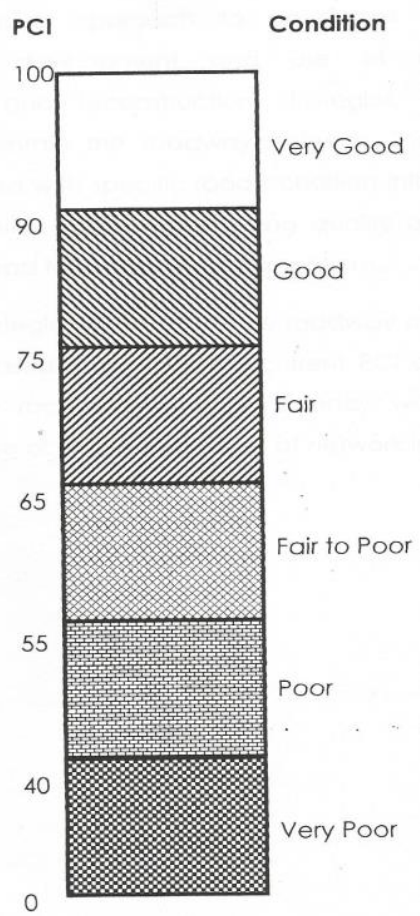

Fig. 2. Pavement Condition Index (PCI) scale [10].

The first premise is useful in establishing a target value for the proper PCI rating of pavements that are in a certain state or condition. Roadways scheduled for rehabilitation and resurfacing are also rated by the PCI procedure.

\section{METHODOLOGY}

In order to apply the road rating systems, the directional lanes of multilane roadways were considered separate roadways by the monitoring procedure. On multilane roadways, the heaviest travelled lane (usually the outside lane) was rated. For two lane roadways, rating of one direction was sufficient unless a significant difference in condition was observed between the two lanes. The monitoring procedure was used to check the variance of the rating systems within a section to limit section length. This limitation produced sections that had a fairly constant visual condition.

The PSR was established by observation and required judgement on the part of the individual rating the road. The panel of raters comprised of twenty road users that plied the routes and based their rating on a 0 to 5 scale.

The PSI, on the other hand, was based on physical objective measurements which are inputted into equation 1 so as to give the pavement condition. The slope variance which relates the difference in elevation of two points $20 \mathrm{~m}$ apart was measured with the aid of a levelling instrument while the other parameters namely rut depth, patching area and the cracking area were determined by using a meter rule.

Lastly, the PCI was also determined by recording the visual distresses along the pavement. It involved three steps as follows:

- The rating team rode over sections of the roadway at a speed of $60 \mathrm{~km} / \mathrm{h}$ during which readily visible distresses such as potholes, cracking, rutting and surface deterioration were rated.

- A second pass along the routes was made with stops at approximately $7.5 \mathrm{~m}$. At each stop, the road was evaluated by viewing $30 \mathrm{~m}$ of the pavement section. Close inspection of cracking, rutting, travelling and other visible distresses were made by viewing the pavement from the roadway shoulder. 
- Using the flexible Pavement Condition Rating form, calculations were made on the basis of the visible distresses which were observed for the major road sections. Weights of the distresses were obtained from the rating form while the deduct points were summed up for each type of observable distresses. The PCI was then calculated using equation 2.

\subsection{The Study Area}

The study area is Akure which is a typical Yoruba town and a relatively largely populated settlement in Nigeria. It was apparently sited along the busy Ileha-Benin road which was the only link between the east and the west during the colonial period. Akure has been the capital of Ondo state since 1976 and it shares boundaries with states like Edo, Osun, Ekiti, Kogi and Delta States. It is located within the tropical rain forest belt of SouthWestern Nigeria approximately on longitude $5^{\circ} 14^{\prime}$ East of the Greenwich Meridian and latitude $7^{\circ} 15^{\prime}$ North of the equator. Akure is approximately $370 \mathrm{~m}$ above the sea level and spreads over an area of about 17 square kilometers.

The five major roads considered in this study were selected on the basis of their strategic location within the city. Each road is defined between two junctions or gates as follows:

- Onyearugbulem junction to Roadblock junction (designated as route 1);

- $\quad$ Onyearugbulem junction to Araromi junction (designated as route 2);

- $\quad$ FUTA south gate to FUTA north gate (designated as route 3);

- Hospital road (High court junction) to Ijoka (Alakure comprehensive school gate) (designated as route 4);

- $\quad$ First bank junction to Oba Ile (Housing Estate junction) (designated as route 5).

The lengths of these routes were obtained from the Civil Engineering Department of the Ministry of Works, Akure while the widths were measured with the aid of a measuring tape.

\section{ANALYSIS AND INTERPRETATION OF RESULTS}

Each route is assessed by using the five road rating systems discussed in section 2.

\subsection{Analysis of Route 1}

Route length $-2 \mathrm{~km}$ (approximately);

Route width - $11.9 \mathrm{~m}$;

Observable distresses: edge cracking, block cracking, alligator cracking, patching and rutting.

- Application of the PSR to Route 1

15 people rated this route a score of 4 (good)

5 rated this route a score of 3 (fair)

On the average:

$\frac{(15 \times 4)+(5 \times \mathrm{x})}{20}=\frac{75}{20}=3.75$

Therefore, the pavement condition is good.

- Application of the PSI to Route 1

Using equation 1 and given the following:

$\mathrm{S}_{\mathrm{v}}-0.015 \mathrm{~m}$

$\mathrm{R}_{\mathrm{d}}-0.14 \mathrm{~m}$

$\mathrm{P}$ for the first spot $=24.10 \times 5.20$

$$
=125.32 \mathrm{~m}^{2}
$$

$\mathrm{P}$ for the second $\mathrm{spot}=11.6 \times 2.8$ $=32.48 \mathrm{~m}^{2}$

P for the third spot $=9.8 \times 6.02$

$$
=58.996 \mathrm{~m}^{2}
$$

$\mathrm{P}$ for the fourth spot $=5.4 \times 5.55$

$: \sum \mathrm{P}=246.766 \mathrm{~m}^{2}$

$$
=29.97 \mathrm{~m}^{2}
$$

C for the first spot (block cracking) $=11.9 \times 77.1$ 
C for the second spot $($ block cracking $)=23.1 \times 5.4$

$$
=124.74 \mathrm{~m}^{2}
$$

$\mathrm{C}$ for the third spot $($ block cracking $)=11.36 \times 3.124$

$$
=35.489 \mathrm{~m}^{2}
$$

$\mathrm{C}$ for the fourth spot (block cracking) $=17.89 \times 0.3$

$$
=5.368 \mathrm{~m}^{2}
$$

C for the fifth spot (alligator cracking) $=11.36 \times 5.90$

$$
=67.75 \mathrm{~m}^{2}
$$

$\mathrm{C}$ for the sixth spot (edge cracking) $=0.6 \times 0.41$

$$
=0.246 \mathrm{~m}^{2}
$$

$\mathrm{C}$ for the seventh spot (edge cracking) $=0.8 \times 0.34$

$$
=0.272 \mathrm{~m}^{2}
$$

$\mathrm{C}$ for the eighth spot (edge cracking $)=0.4 \times 0.52$

$\therefore . \Sigma \mathrm{C}=1151.563 \mathrm{~m}^{2}$

$$
=0.208 \mathrm{~m}^{2}
$$

Substituting these values into equation 1 gives:

$$
\begin{aligned}
& \text { PSI }=5.02-1.9 \log (1+0.015)-1.38(0.14)^{2}-0.01(246.776+1151.563)^{1 / 2} \\
& =5.02-0.12-0.03-0.39 \\
& =4.48 \\
& \text { Therefore, the condition of the pavement is very good. }
\end{aligned}
$$

- Application of the PCI to Route 1

Using equation 2 and the flexible pavement rating in Table 1, the following are obtained:

a) Weight of edge cracking with low severity and occasional extent (Table 1)

$$
=5(0.4)(0.5)
$$

$=1$

Weight of edge cracking at three different spots

$=1 \times 3=3$

b) Weight of block cracking with high severity and extensive extent (Table 1)

$=10(1)(1)$

$=10$

Weight of block cracking at one spot

$=10 \times 1=10$

c) Weight of block cracking with low severity and occasional extent (Table 1)

$=10(0.4)(0.5)$

$$
=2
$$

Weight of block cracking at three different spots

$$
=2 \times 3=6
$$

d) Weight of wheel track cracking with low severity and occasional extent (Table 1) $=15(0.4)(0.5)=3$

Weight of wheel track cracking at one spot

$$
=3 \times 1=3
$$

e) Weight of patching with high severity and occasional extent (Table 1)

$=5(1)(0.6)$

$=3$

Weight of patching at one spot

$=3 \times 1=3$

f) Weight of rutting with high severity and occasional extent (Table 1)

$=10(0.3)(0.6)$

$=1.8$

Weight of rutting at one spot

$=1.8 \times 1=1.8$

$\sum$ Deduct points $=3+10+6+3+3+1.8$

$$
=26.8
$$

PCI $=100-26.8$

$=73.2$ 
Therefore the pavement condition is fair based on the PCI scale in Figure 2.

Table 1. Flexible pavement ratings [10].

\begin{tabular}{|l|c|c|c|c|c|c|c|c|l|}
\hline \multirow{2}{*}{ Distress } & Distress & \multicolumn{2}{l|}{ Severity weight } & \multicolumn{3}{l|}{ Extent weight } & Deduct \\
& Weight & P & M & H & O & F & E & Points \\
\hline RAVELING & 10 & 0.3 & 0.6 & 1 & 0.5 & 0.8 & 1 & \\
\hline BLEEDING & 5 & 0.8 & 0.8 & 1 & 0.6 & 0.9 & 1 & \\
\hline PATCHING & 5 & 0.3 & 0.6 & 1 & 0.6 & 0.8 & 1 & \\
\hline POTHOLES/DEBONDING & 10 & 0.4 & 0.7 & 1 & 0.5 & 0.8 & 1 & \\
\hline CRACK SEALING DEFICIENCY & 5 & 1 & 1 & 1 & 0.5 & 0.8 & 1 & \\
\hline RUTTING & 10 & 0.3 & 0.7 & 1 & 0.6 & 0.8 & 1 & \\
\hline SETTLEMENT & 10 & 0.5 & 0.7 & 1 & 0.5 & 0.8 & 1 & \\
\hline CORRUGATIONS & 5 & 0.4 & 0.8 & 1 & 0.5 & 0.8 & 1 & \\
\hline WHEEL TRACK CRACKING & 15 & 0.4 & 0.7 & 1 & 0.5 & 0.7 & 1 & \\
\hline BLOCK AND TRANSVERSE & 10 & 0.4 & 0.7 & 1 & 0.5 & 0.7 & 1 & \\
CRACKING & & & & & & & & \\
\hline LONGITUDINAL JOINT CRACKING & 5 & 0.4 & 0.7 & 1 & 0.5 & 0.7 & 1 & \\
\hline EDGE CRACKING & 5 & 0.4 & 0.7 & 1 & 0.5 & 0.7 & 1 & \\
\hline RANDOM CRACKING & 5 & 0.4 & 0.7 & 1 & 0.5 & 0.7 & 1 & \\
\hline
\end{tabular}

where O - Occasional, F - Frequent, E - Extensive, L - Low, M - Medium, H - High.

Table 2 shows the summary of the results obtained after applying the three pavement rating condition systems to each of the five routes.

Table 2. Summary of results on application of the road rating systems.

\begin{tabular}{|l|l|l|l|l|c|c|}
\hline \multicolumn{2}{|l|}{$\begin{array}{l}\text { Pavement Condition } \\
\text { Rating System }\end{array}$} & Route 1 & Route 2 & Route 3 & Route 4 & Route 5 \\
\hline \multirow{2}{*}{ PSR } & Value & 3.75 & 2.65 & 4.75 & 2.9 & 3.5 \\
\cline { 2 - 7 } & Condition & Good & Fair & Very good & Fair & Good \\
\hline \multirow{2}{*}{ PSI } & Value & 4.48 & 4.6 & 4.80 & 4.91 & 4.87 \\
\cline { 2 - 7 } & Condition & Very good & Very good & Very good & Very good & Very good \\
\hline \multirow{2}{*}{ PCI } & Value & 73.2 & 51.9 & 95.2 & 4.35 & 62.4 \\
\cline { 2 - 7 } & Condition & Fair & Poor & Very good & Poor & Fair to poor \\
\hline
\end{tabular}

Table 2 shows that the same road rating conditions of "very good" were obtained for all the routes using the PSI. Also, the three rating systems gave the same condition rating for route 3 as "very good". The PSR and PSI gave very close values of 4.75 and 4.80 respectively for route 3 . Routes 2 and 4 have the lowest condition ratings in terms of the PSR while routes 1,2, 4 and 5 have the lowest condition rating in terms of the PCI. The best condition rating was obtained for route 3 using the three road rating systems.

\section{CONCLUSION}

Considering the three road rating systems used in this study, the PCI gives the most reasonable ratings for the roads based on the fact that it accommodates the different distresses experienced in highway pavements.

It appears that the PSI is the least effective due to the fact that it accommodates only three of the distresses experienced in highway pavements namely rutting, cracking and patching. In this study, it gives the same condition rating for all the routes which is not realistic.

The PSR also gives realistic values and condition ratings however, it may not be generally acceptable because of its subjective nature. In order to make it acceptable, the panel of raters should comprise of highway engineers with adequate knowledge and experience to carry out the ratings.

Considering all the rating systems, it appears that routes 1,2, 4 and 5 require the most attention in terms of rehabilitation/maintenance efforts. Route 3 requires little or no rehabilitation efforts since it scored a condition rating of "very good" for all the rating systems. 


\section{REFERENCES}

[1] Garber, N.J., Hoel, L. A., Traffic and highway engineering, Fourth edition, Cengage learning, Toronto, Canada, 2009, p. 4-6.

[2] Mathew, T.V., Transportation engineering I, Lecture notes in transportation systems engineering, Civil engineering department, Indian Institute of Technology, Bombay, 2006, p. 123-126.

[3] Tarawneh, S., Sarireh, M., Causes of cracks and deterioration of pavement on highways in Jordan from contractors' perspective. Civil and environmental research journal of the international institute for science, technology and education (IISTE), vol. 3, no. 10, 2013.

[4] Yoder, E.J., Witczak, M.W., Principles of pavement design, Second edition, John Wiley and Sons Inc., New York, USA, 1975, p. 15-18.

[5] Fwa, T.F., The Handbook of highway engineering, CRC Press, Boca raton, Florida, 2006, p. 8.

[6] Rangwala, S. ., Rangwala, K.S., Rangwala, P.S., Highway engineering, Charotar publishing house, India, 2007, p. 362-363.

[7] Al-Qadi, I.M., Sayed, T., Alnuaimi, N., Masad, E., Efficient transportation and pavement systems: characterization, mechanisms, simulation and modeling, CRC Press, Boca raton, Florida, United States, 2008 , p. 337.

[8] O’Flaherty, C.A., Highway engineering, Volume 2, Edward arnold publishers, London, 1974.

[9] Hicks, R.G., Mahoney, J.P., Collection and use of pavement condition data, NCHRP Synthesis 76, Transportation research board, Washington D.C, 1981.

[10] Haas, R., Hudson, W.R., Zaniewski, J., Modern pavement management, Krieger publishing, Malabar, Florida, 1994 